NBER WORKING PAPER SERIES

\title{
A SIMPLE MAPPING FROM MPCS TO MPXS
}

\author{
David Laibson \\ Peter Maxted \\ Benjamin Moll \\ Working Paper 29664 \\ http://www.nber.org/papers/w29664
NATIONAL BUREAU OF ECONOMIC RESEARCH
1050 Massachusetts Avenue
Cambridge, MA 02138
January 2022

This research was supported by grants from the Pershing Square Fund for Research on the Foundations of Human Behavior, the Leverhulme Trust, and the European Union's Horizon 2020 research and innovation programme under grant number No. GA: 865227. The views expressed herein are those of the authors and do not necessarily reflect the views of the National Bureau of Economic Research.

NBER working papers are circulated for discussion and comment purposes. They have not been peer-reviewed or been subject to the review by the NBER Board of Directors that accompanies official NBER publications.

(C) 2022 by David Laibson, Peter Maxted, and Benjamin Moll. All rights reserved. Short sections of text, not to exceed two paragraphs, may be quoted without explicit permission provided that full credit, including $(\odot$ notice, is given to the source. 
A Simple Mapping from MPCs to MPXs

David Laibson, Peter Maxted, and Benjamin Moll

NBER Working Paper No. 29664

January 2022

JEL No. C82,D11,D15,E21,E60,E62,G50,H31

\begin{abstract}
$\underline{\text { ABSTRACT }}$ between nondurable and durable consumption. Such notional-consumption models generate discussions often highlight marginal propensities for expenditure (MPX), which incorporate spending on a durable stock. We compare the notional-consumption model to an isomorphic model with a durable stock, and map notional MPCs into MPXs. The mapping is especially interest rate $r$, and durable depreciation rate $d$.

David Laibson

Department of Economics

Littauer M-12

Harvard University

Cambridge, MA 02138

and NBER

dlaibson@gmail.com

Peter Maxted

Haas School of Business

University of California Berkeley

maxted@ haas.berkeley.edu

Benjamin Moll

London School of Economics

Houghton Street

London WC2A $2 \mathrm{AE}$

United Kingdom

b.moll@1se.ac.uk
\end{abstract}

Standard consumption models assume a notional consumption flow that does not distinguish notional marginal propensities to consume (MPC). By contrast, empirical work and policy simple for a one-period horizon: $M P X=(1-s+s /(r+d)) \times M P C$, with durable share $s$, real 


\section{Introduction}

The most widely used class of consumption models assumes that households maximize the present discounted value of flow utility, where flow utility is a function of a scalar index, $c_{t}$, representing flow consumption. This model simplifies the economy by modeling all consumption as if it were a notional ${ }^{1}$ flow of homogeneous consumption. This notional-consumption model does not specify the sources of this flow; in particular, the model does not distinguish between durable and nondurable consumption. This model is often used to analyze the response of notional consumption to liquidity injections, i.e., what we call the notional MPC.

In most practical macroeconomic policy analysis, notional consumption is not the key variable. Macroeconomic stimulus attempts to raise the value of personal consumption expenditures ( $\mathrm{C}$ in the national accounts; $\mathrm{GDP}=\mathrm{C}+\mathrm{I}+\mathrm{G}+\mathrm{NX}$ ), not the flow of notional consumption. To illustrate the difference, assume a domestic firm manufactures an automobile in January (using domestic parts and labor) and sells it to a household in February for price $p$. Holding all else equal, the production/sale of this automobile raises GDP in Q1 by the market price $p$, but raises notional consumption in Q1 by an amount that is approximately two orders of magnitude smaller than $p$ because notional consumption is the household's consumption flow from owning the new automobile, which accrues only slowly over time. For most policy applications, economists need to understand the dynamics of consumption expenditure. We refer to the response of expenditure to liquidity injections as the marginal propensity for expenditure $(\mathrm{MPX}) .^{2}$

The relationship between notional consumption and consumption expenditure is complex. The two measures are identical for goods that have no durability (e.g., lettuce) and for services. $^{3}$ The low rates of depreciation for durable goods ${ }^{4}-$ such as home furnishings and automobiles - generate a large wedge between notional consumption of durables and expenditure on durables, even in data that is time-aggregated to annual periods.

The discrepancy between notional consumption and consumption expenditure has long

\footnotetext{
${ }^{1}$ In this model consumption is "notional" because it is a theoretical concept without a clear empirical counterpart.

${ }^{2}$ Our MPX notation is similar to Auclert (2019) and Crawley and Kuchler (2020).

3 "Services are commodities that cannot be stored or inventoried and that are usually consumed at the place and time of purchase." Bureau of Economic Analysis (2020)

4 "Durable goods are goods that have an average useful life of at least 3 years." Ibid.
} 
been recognized and discussed in the economics literature. ${ }^{5}$ Especially in empirical work, economists frequently draw a distinction between the MPX on all expenditures (including both durables and nondurables) and the MPX on nondurables alone. Estimates of the quarterly MPX for all expenditure range from 50-90\%, while estimates of the quarterly MPX for nondurable expenditure range from $15-25 \% .{ }^{6}$ In theory, the notional MPC lies below the total MPX and above the MPX on nondurables.

In this paper, we propose a portable and tractable modeling device that converts a notional MPC into an MPX. In particular, we show how to extend a notional-consumption model to generate predictions about consumption expenditures in a model with durable stocks. We provide a parsimonious equation for calculating MPXs in the model with durables.

Our modeling device can be built in both continuous and discrete time. Though the continuous-time specification is generally more tractable, our discrete-time MPX formula is especially simple when used to calculate the MPX over one period:

$$
\text { Total MPX }=\left(1-s+\frac{s}{r+\delta}\right) \times \text { Notional MPC, }
$$

where $s$ is the durable share of notional consumption, $r$ is the real interest rate, and $\delta$ is the depreciation rate for durables (so that $r+\delta$ is the user cost of durables). This total MPX sums the MPX on nondurables, $(1-s) \times$ MPC, and the MPX on durables, $\left(\frac{s}{r+\delta}\right) \times \operatorname{MPC}$.

We use BEA data to calibrate $s=0.125$ and a quarterly depreciation rate for consumer durables of $\delta=0.054 .^{7}$ Assuming a small quarterly real interest rate $(r \approx 0)$, our model yields $1-s+\frac{s}{r+\delta}=3.2$ and hence a rule-of-thumb for calculating the quarterly MPX in a model of notional consumption: take the MPC and multiply by 3. For example, the seminal paper of Kaplan and Violante (2014) predicts a quarterly notional MPC of 15\%, and our rule-of-thumb therefore implies a quarterly MPX of $45 \%$.

Our framework can also be used to move back and forth between total MPXs and MPXs

\footnotetext{
${ }^{5}$ See for example Mankiw (1982), Hayashi (1985), Lusardi (1996), Padula (2004), Parker et al. (2013), Jappelli and Pistaferri (2014), and Kueng (2018). Aguiar and Hurst (2005) emphasize a separate, but related, distinction of consumption versus expenditure, where consumption includes home production.

${ }^{6}$ Kaplan and Violante (2021) review nondurables, and Di Maggio et al. (2020b) review total spending. Kaplan and Violante (2021) review the determinants of notional MPCs in heterogeneous-agent models.

${ }^{7}$ Appendix $\mathrm{C}$ provides details, and also reports a calibration that includes housing.
} 
on nondurables. In our one-period discrete-time specification,

$$
\text { Notional MPC }=\left(\frac{1}{1-s}\right) \times \text { Nondurable MPX. }
$$

Accordingly,

$$
\text { Total MPX }=\left(1+\frac{s}{(r+\delta)(1-s)}\right) \times \text { Nondurable MPX, }
$$

or about 3.6 in our calibration.

To derive our MPX formula, our extended model with purchased durables makes a number of assumptions (see Assumptions 1 to 3 in Section 3.2). The strongest (and most indispensable) of these is that durables are liquid, i.e., households do not face adjustment frictions when buying and selling durables. Auclert et al. (2018) use the same assumption to map predictions of a notional-consumption model into predictions about expenditure in a model with durables, though they do not flesh out the MPC versus MPX distinction. ${ }^{8}$ Similarly, Abel (1990) and Auclert (2019) use this assumption to discuss the relative size of different MPX measures but they do not provide a mapping from notional-consumption models to models with durables. ${ }^{9}$ In Section 5 we discuss various shortcomings of our approach, including the frictionless durables assumption, and how they can be partially addressed.

Despite the strong assumptions we make, our simple model fits the available data well. For example, Parker et al. (2013) estimate quarterly MPXs on nondurables of 12-30\% and quarterly total MPXs of 50-90\%, while our framework comparably maps a 12\%-30\% MPX on nondurables into a total MPX of $43 \%-108 \%{ }^{10}$

\footnotetext{
${ }^{8}$ See Appendix E of Auclert et al. (2018). Our mapping is simpler than theirs because other assumptions differ. For example, we assume CES preferences over nondurables and durables whereas they assume that preferences are separable between the two goods. Another related mapping is by Fagereng et al. (2019b, Appendix B.1) who analyze a model with liquid housing and map it to a notional-consumption model with a time-varying consumption price index.

${ }^{9}$ See Section 3 of Abel (1990) and Appendix A.5 of Auclert (2019). The relation to Abel's work is especially simple: in the one-period discrete-time special case, our formula for the MPX on durables is $\left(\frac{s}{r+\delta}\right) \times$ MPC and the MPX on nondurables is $(1-s) \times$ MPC so that the ratio of the two is $\frac{1}{r+\delta} \frac{s}{1-s}$. This is identical to Abel's equation (30b) (although he assumes Cobb-Douglas and we assume CES preferences). Auclert (2019) instead derives an expression for the total MPX as a multiple of the MPX on nondurables but this expression differs from the analogue in our framework $\left(1+\frac{s}{(r+\delta)(1-s)}\right)$ because of different assumptions on preferences.

${ }^{10} 43 \%=3.6 \times 12 \%$ and $108 \%=3.6 \times 30 \%$. As we discuss in Section 4.1, MPXs are not bounded above by $100 \%$. For example, a consumer who uses a $\$ 1,000$ liquidity injection to make a downpayment on a $\$ 30,000$ car has a $3,000 \%$ MPX.
} 
Section 2 discusses the importance of having a modeling tool that maps between notional MPCs and MPXs. Section 3 lays out a notional-consumption model and our isomorphic model with durables. Section 4 presents our main results about converting notional MPCs into MPXs, while Section 5 discusses shortcomings and partial fixes. Section 6 concludes.

\section{MPCs versus MPXs: An Important Distinction}

\section{$2.1 \quad$ Terminology}

We begin by defining our terminology. Whenever we use the term consumption we mean notional consumption, i.e., the utility-generating consumption flows that are studied in classical consumption models. Accordingly, whenever we use the term MPC we mean a notional MPC.

In contrast to notional consumption, the alternative concept that we study is expenditure. We refer to the response of expenditure to liquidity injections as the MPX. The difference between consumption and expenditure derives from durability. The purchase of a durable good generates a one-time burst of expenditure but a long-lasting flow of notional consumption. ${ }^{11}$ Unless specified otherwise, MPX refers to the total MPX, which includes spending on nondurables and durables.

\subsection{The Importance of Mapping MPCs Into MPXs}

Given a model of notional consumption and notional MPCs, there are two broad reasons why it is important to develop a mapping from MPCs into MPXs. The first reason is measurement: developing a mapping from MPCs into MPXs enables a closer connection between model predictions and empirical moments. The second reason is policy: policy makers should possess models of the expenditure response to liquidity shocks, as it is consumer expenditure rather than notional consumption that matters for the response of GDP to stabilization policy. These reasons are detailed in turn below.

Starting with measurement considerations, it is important to differentiate MPXs from

\footnotetext{
${ }^{11}$ In our terminology, the MPC on nondurables and services equals the MPX on nondurables and services. However, the total MPC (which includes both nondurable and durable consumption flows) will not equal the total MPX (which includes both nondurable and durable expenditures).
} 
MPCs both in order to understand the underlying connection between spending and consumption flows, and to align notional-consumption models with a broader set of empirical moments. Total MPXs frequently differ from nondurable MPXs in the data because durable expenditures are an important part of the household spending response to liquidity injections. For example, Parker et al. (2013) estimate that households spent 12-30\% of the 2008 fiscal stimulus on nondurable goods within the first three months, but spent $50-90 \%$ of the stimulus in total over the same period. Kueng (2018) estimates that households spent $25 \%$ of payments from the Alaska Permanent Fund on nondurables over the first three months, but total expenditure accounted for $73 \%$ of the payment. The literature is reviewed in Di Maggio et al. (2020b), who suggest that nondurable MPXs are typically estimated to be around 20\%, while estimates of total MPXs range from $60-80 \%$.

Additionally, linking MPXs and MPCs enables models of notional consumption to speak to a wider variety of empirical moments, and vice versa. This is especially important given the rise of administrative data on household balance-sheets, which sometimes enables researchers to impute the total expenditure response to liquidity injections, but may not allow for a decomposition of total expenditure into its nondurable and durable components (see e.g. the discussions in Fagereng et al. (2019a) and Crawley and Kuchler (2020), both of whom impute MPXs from administrative balance-sheet data). ${ }^{12}$ Alternatively, data on household spending is often only partial. Automobile-purchase data is a leading example of this, with credit-bureau data being used to understand the effect of shocks on automobile purchases (e.g., Di Maggio et al., 2017, 2020a). Another example is account-level data, which provides an accurate and high-frequency measure of a subset of consumer spending (e.g., Ganong and Noel, 2019; Ganong et al., 2021), but may miss large durable purchases such as automobiles. In both cases, our modeling device can be used to convert these partial MPXs into partial MPCs, thus providing a lower bound on the underlying notional-consumption response.

Turning to policy considerations, differentiating MPXs from MPCs matters for understanding the impact of policy on economic output. Indeed, personal consumption expenditures (PCE) - the "consumption" component of GDP - is composed of consumer expenditures on durables, nondurables, and services. That is, PCE is a measure of expenditure; it

\footnotetext{
${ }^{12}$ Similar issues can also arise in survey data. For example, as discussed in Jappelli and Pistaferri (2014), the frequently used Italian Survey of Household Income and Wealth (SHIW) asks how much consumers would spend following a positive liquidity injection, but does not separate spending into nondurables versus durables.
} 
is not a measure of the utility-generating notional consumption that is typically modeled. Policy makers should have models that identify both MPXs and MPCs, and our MPX tool provides a tractable technology for mapping predictions about notional consumption into predictions about expenditure.

Though our modeling framework studies MPCs and MPXs in partial equilibrium, such partial-equilibrium expenditure responses are important inputs to fuller general-equilibrium analyses. We highlight two specific ways in which the distinction between MPXs and MPCs may be important. First, as discussed above, durable purchases compose an appreciable part of the expenditure response to liquidity injections: quarterly total MPXs are three to four times larger than quarterly nondurable MPXs. One timely example for the relevance of this distinction can be found in recent discussions about the optimal magnitude of the fiscal response to the COVID-19 pandemic. Notional-consumption models can make predictions about how pandemic environments affect households' consumption response to fiscal stimulus (e.g., Kaplan et al., 2020). However, for important policy questions such as evaluating the magnitude of fiscal stimulus relative to the output gap, policy makers need predictions about the response of consumer expenditures, not just notional consumption. Our MPX tool enables this mapping.

Second, the timing of MPXs may differ from MPCs. In particular, expenditures will be more front-loaded than consumption if expenditures are used to purchase durables that provide long-lasting consumption flows. ${ }^{13}$ Section 4.2 makes this point analytically, while Appendix E applies our MPX technology to the model of Laibson et al. (2021) and finds significant front-loading of MPXs relative to MPCs. This is consistent with the results in Kueng (2018), who documents front-loading of durable relative to nondurable expenditure.

Despite these observations highlighting the importance of understanding MPXs, we do not want to imply that economists should therefore overlook MPCs. From a normative perspective, notional consumption is a key construct, because this is the argument in the utility function. More generally, which concept is more relevant depends on the question being asked, highlighting the value of a simple and tractable mapping between the MPC and the MPX.

\footnotetext{
${ }^{13}$ One offsetting effect is that durables are more import-intensive than nondurables and services (Hale et al., 2019). Nonetheless, modeling such considerations still requires a decomposition of consumption into durable and nondurable components, which is the goal of our MPC-MPX mapping.
} 


\section{The Household Balance Sheet}

Here we develop our modeling device for mapping notional consumption into expenditure. We present this framework in continuous time for tractability and expositional simplicity. However, because many consumption-saving models are written in discrete time we also provide a version in discrete time. Our main discrete-time MPX results are presented in Section 4.3, with details provided in Appendix B.

We begin by summarizing our approach for building the MPX modeling device. In Section 3.1 we present a standard consumption-saving model with a single notional consumption good. We refer to this model as the Benchmark, since the majority of economic models study notional consumption flows and do not decompose notional consumption into durable and nondurable components.

Next, in Section 3.2 we introduce an extended model that explicitly models the purchase of durables. This extended model is designed specifically to: (i) be isomorphic to the Benchmark, and (ii) deliver a tractable MPX formula. The isomorphism implies that a researcher can take an existing model of notional consumption that makes predictions about MPCs and use it directly to calculate MPXs.

\subsection{Benchmark: Single Notional Consumption Good}

Let $b_{t}$ and $y_{t}$ denote a household's liquid wealth and income at time $t$. Income $y_{t}$ can follow an arbitrary Markov process. Let $r$ denote the interest rate on liquid wealth. The household's notional consumption flow is denoted $c_{t}$. The budget constraint is:

$$
\dot{b}_{t}=y_{t}+r b_{t}-c_{t}
$$

Households also face a borrowing constraint: $b_{t} \geq \underline{b}$.

The state variables of the notional-consumption model are $x_{t}=\left(b_{t}, y_{t}\right)$. We denote the consumption policy function by $c_{t}=c\left(x_{t}\right)$. We also denote by

$$
C_{\tau}=\int_{0}^{\tau} c_{t} d t
$$

the cumulative notional consumption flow over a discrete time interval of length $\tau$. This 
cumulative flow will play an important role because the numerator of an MPC is the integral of marginal consumption over a discrete time interval.

For simplicity we only model a liquid asset, since this is the asset that is used to fund consumption. However, our results do not rely on the single-asset framework described here. Our modeling tool is portable and it applies in richer environments, including those with multiple assets with specific return and liquidity features. To demonstrate this portability, Appendix E applies our MPX tool to the model of Laibson et al. (2021), which includes liquid wealth, houses, mortgages, and a wedge between the interest rates on deposits and credit card debt.

\subsection{Extension: An Isomorphic Model with Durables}

To bridge the gap between consumption and expenditure, we now introduce an extended model featuring the purchase of durable goods (the model can also allow for rentals, as discussed at the end of this section). The key feature of this extension is that durables are modeled such that the extended model with durables is isomorphic to the notionalconsumption model in Section 3.1. This extension is not meant to rigorously model the household's durable expenditure, and is best thought of as providing an accounting formula to decompose notional consumption into nondurable and durable expenditure. The goal of our approach is to provide a simple and tractable method for connecting MPCs to MPXs. ${ }^{14}$ Our methodology is general and can be applied in a wide range of economic models.

Setup with Durables. The household can now consume two different goods: durables and nondurables. Let $n_{t}$ denote nondurable consumption, which the household purchases as a flow. To consume durables, the household must purchase a stock of durables $D_{t} \geq 0$. Durable stock $D_{t}$ provides durable consumption as a flow, and depreciates at rate $\delta$ satisfying $r+\delta>0$. In keeping with our partial equilibrium analysis, the price of durables is exogenous and we normalize it to one. The household continues to save in liquid bank holdings, which we now denote by $\ell_{t}$. Total wealth is given by $b_{t}=\ell_{t}+D_{t}$.

Our extension with durables is isomorphic to the notional-consumption model under

\footnotetext{
${ }^{14}$ For a rigorous evaluation of the impact of durables on macroeconomic stabilization policy, see for example Berger and Vavra (2015), McKay and Wieland (2019), and Beraja and Wolf (2021). See also Yogo (2006) for an asset-pricing analysis.
} 
three (strong) assumptions which we spell out momentarily. The key idea for establishing the isomorphism is to make assumptions such that

$$
c_{t}=n_{t}+(r+\delta) D_{t}, \quad \text { with } \quad n_{t}=(1-s) \times c_{t} \quad \text { and } \quad(r+\delta) D_{t}=s \times c_{t}
$$

for some $s \in[0,1]$. In words, notional flow consumption expenditure $c_{t}$ is the sum of nondurable flow consumption expenditure $n_{t}$ and the implied rental cost (user cost) of durables $(r+\delta) D_{t}$, with the latter equaling a constant share $s$ of the notional consumption flow. This can be justified with the three assumptions below. Alternatively, (3) can be viewed as a direct assumption on household behavior akin to the constant-saving rate assumption in a Solow model.

Our most important and indispensable assumption is:

Assumption 1 The durables market is perfectly liquid. The household can buy and sell durables instantaneously at price $p \equiv 1$; there are no transaction costs or time delays. Further, the household can borrow (short-term) against durables at the market rate $r$.

With this assumption, the household's liquid bank holdings $\ell_{t}$ and durables $D_{t}$ evolve as

$$
\begin{aligned}
d \ell_{t} & =\left[y_{t}+r \ell_{t}-n_{t}\right] d t-d \psi_{t} \\
d D_{t} & =-\delta D_{t} d t+d \psi_{t}
\end{aligned}
$$

Because durable purchases can be lumpy so that $D_{t}$ can jump discontinuously, we introduce process $\psi_{t}$ to record the household's cumulative spending on durables from time 0 to time $t$, and denote by $d \psi_{t}$ the household's purchases of durables at time $t$.

Importantly, note the absence of adjustment costs in equations (4) and (5). This is a direct consequence of Assumption 1. Similarly, because Assumption 1 establishes that the household can borrow against durables, the borrowing constraint now applies to the household's total liquid wealth holdings $b_{t}=\ell_{t}+D_{t}$ :

$$
\ell_{t}+D_{t} \geq \underline{b}
$$

Given Assumption 1 we can work with only one state variable for household wealth, namely 
total liquid wealth $b_{t}=\ell_{t}+D_{t}{ }^{15}$ To this end, sum (4) and (5) as $d \ell_{t}+d D_{t}=\left[y_{t}+r \ell_{t}-n_{t}-\delta D_{t}\right] d t$, or

$$
\dot{b}_{t}=y_{t}+r b_{t}-n_{t}-(r+\delta) D_{t}
$$

A key implication of Assumption 1 is therefore that a relevant measure of the household's expenditure on durables is the user cost $(r+\delta) D_{t}$.

We next make two additional assumptions to obtain (3).

Assumption 2 The household values total notional flow consumption, which is given by the CES aggregator

$$
c_{t}=\left(s^{\frac{1}{\eta}}\left(f D_{t}\right)^{\frac{\eta-1}{\eta}}+(1-s)^{\frac{1}{\eta}} n_{t}^{\frac{\eta-1}{\eta}}\right)^{\frac{\eta}{\eta-1}},
$$

where $n_{t}$ is the nondurable consumption flow, $f D_{t}$ is the durable consumption flow generated by the durable stock $D_{t}, s \in[0,1]$ is the utility weight on durable consumption, and $\eta>0$ is the elasticity of substitution between durables and nondurables.

Given the CES functional form in equation (8) we obtain the following result:

Lemma 1 Let $R:=(r+\delta) / f$ denote the price of a unit of durable flow utility. Under Assumptions 1 and 2 the optimal intratemporal choices of nondurables and durables are given by

$$
n_{t}=\frac{1-s}{s R^{1-\eta}+1-s} P c_{t}, \quad f D_{t}=\frac{s R^{-\eta}}{s R^{1-\eta}+1-s} P c_{t}
$$

where

$$
P=\left(s R^{1-\eta}+1-s\right)^{\frac{1}{1-\eta}}
$$

Finally, the expenditure required to attain notional consumption flow $c$ is

$$
n_{t}+(r+\delta) D_{t}=P c_{t}
$$

Our third and final Assumption completes the derivation of (3).

Assumption 3 The utility flow per unit of durable $f$ equals its user cost, $f=r+\delta$.

\footnotetext{
${ }^{15}$ Without Assumption 1 we would need to keep track of $\ell_{t}$ and $D_{t}$ as separate state variables.
} 
With Assumption 3 we see from Lemma 1 that $R=1$, and therefore also that the CES price index $P=1$. Using this in equations (9) and (11) we obtain

$$
n_{t}=(1-s) \times c_{t}, \quad f D_{t}=s \times c_{t}, \quad \text { and } \quad n_{t}+(r+\delta) D_{t}=c_{t},
$$

which is the key result (3) we wanted to derive. When the interest rate $r$ is fixed (as assumed above), the expenditure shares on nondurables and durables in equation (9) and hence the price index $P$ in equation (10) are constant over time and across individuals. Assumption 3 is then a weak assumption that sets this constant price index equal to one. When the interest rate $r$ varies (as it may in other applications), Assumption 3 is instead a very strong assumption which ensures that expenditure shares on nondurables and durables are constant even though their relative prices move, and also that the welfare-relevant price index $P$ stays constant at $P=1 .^{16}$

Isomorphism to Notional-Consumption Model. With Assumptions 1 to 3 in hand we are now ready to prove the isomorphism between the extension with durables and our benchmark notional-consumption model.

Proposition 1 Under Assumptions 1 to 3, the extension with durables is isomorphic to the notional-consumption model. In particular, total liquid wealth $b_{t}=\ell_{t}+D_{t}$ evolves as

$$
\dot{b}_{t}=y_{t}+r b_{t}-c_{t}
$$

subject to the borrowing constraint $b_{t} \geq \underline{b}$. This is identical to the law of motion and borrowing constraint for $b_{t}$ in equation (1).

Proof. Assumption 1 implies that equation (7) holds. Assumptions 2 and 3 imply that equation (3) holds. Substituting (3) into (7) yields equation (12).

\footnotetext{
${ }^{16}$ With a time-varying interest rate and without Assumption 3, our extension with durables would instead be isomorphic to a model with a time-varying price of notional consumption. In particular, equation (12) in Proposition 1 would be $\dot{b}_{t}=y_{t}+r_{t} b_{t}-P_{t} c_{t}$ with a time-varying $P_{t}$ given by (10). This time-varying price $P_{t}$ arises because of movements in the user cost of durables that are caused by corresponding movements in the interest rate $r$. Because the standard notional-consumption model in Section 3.1 does not feature a time-varying price $P_{t}$, Assumption 3 is needed to ensure that it remains constant at $P_{t}=1$. Assumption 3 is a strong assumption in the sense that it shuts down economically meaningful mechanisms, though it only shuts them down because such mechanisms are missing from the standard notional-consumption model.
} 
Note that the extended model has exactly the same state variables $x_{t}=\left(b_{t}, y_{t}\right)$ as the notional-consumption model. Given the assumption of no adjustment costs, the stock of durables $D_{t}$ instead becomes a control variable.

Cumulative Expenditure Flows. Analogous to the cumulative notional consumption flow in equation (2), we here define $X_{\tau}$ to be the cumulative expenditure over a period $\tau$, which is the sum of cumulative expenditure on nondurables $X_{\tau}^{n}$ and durables $X_{\tau}^{D}$ :

$$
X_{\tau}=X_{\tau}^{n}+X_{\tau}^{D}, \quad \text { where } \quad X_{\tau}^{n}=\int_{0}^{\tau} n_{t} d t \quad \text { and } \quad X_{\tau}^{D}=\int_{0}^{\tau} d \psi_{t} .
$$

The cumulative expenditure flow $X_{\tau}$ will be used to define the MPX. Looking at nondurable expenditure $X_{\tau}^{n}$, from equation (3) we have

$$
X_{\tau}^{n}=(1-s) \int_{0}^{\tau} c_{t} d t
$$

meaning that nondurable spending composes share $1-s$ of total cumulative notional consumption. Next consider durable expenditure $X_{\tau}^{D}$. Budget constraint (5) implies that

$$
X_{\tau}^{D}=\int_{0}^{\tau} \delta D_{t} d t+D_{\tau}-D_{0}
$$

Equation (15) shows that expenditure on durables has two components. First, $D_{\tau}-D_{0}$ captures the household's spending to increase their durable stock from $D_{0}$ to $D_{\tau}$. But this is an incomplete measure of durable spending, because some durables have depreciated over period $\tau$ and need to be replaced. Spending to replace depreciated durables is given by $\int_{0}^{\tau} \delta D_{t} d t$.

Aside: Rented Durables. For simplicity this extension assumes that durables are owned by consumers, though in reality some durables are owned and some are rented. For partialequilibrium analyses, durable share $s$ can be calibrated as the share of notional consumption coming from purchased durables, rather than the total durable share. But for generalequilibrium analyses, what matters is the total durable share. It is immaterial whether a household purchases a durable directly or whether a firm purchases the durable and then rents it to the household. In either case, the durable still needs to be produced and this will 
typically be what matters for macroeconomic dynamics.

\section{Results: The MPC and the MPX}

We now present our main result on tractably calculating MPXs from models with (only) notional consumption.

\subsection{Mapping MPCs into MPXs}

We first define MPCs in the notional-consumption model and MPXs in the extended model, and then provide a mapping from the former to the latter using the modeling isomorphism.

First consider the MPC in the notional-consumption model of Section 3.1. The MPC is the fraction of income consumed out of a liquid-wealth windfall over a discrete time interval. It is therefore closely related to the cumulative notional consumption flow in equation (2). More precisely, denote a point in the state space by $x=(b, y) \cdot{ }^{17}$ The notional marginal propensity to consume (MPC) over a period of length $\tau$ for individuals with initial state $x_{0}=x$ is then

$$
M P C_{\tau}(x)=\frac{\partial}{\partial b} \mathbb{E}\left[\int_{0}^{\tau} c\left(x_{t}\right) d t \mid x_{0}=x\right],
$$

i.e., the expected change in cumulative consumption given a change in liquid wealth (Achdou et al., 2021).

Next consider the MPX in the extended model of Section 3.2. The MPX is the fraction of income spent out of a liquidity injection over a discrete time interval. The MPX is closely related to the cumulative expenditure flow defined in equation (13). Again denote a point in the state space by $x=(b, y)$. The marginal propensity for expenditure (MPX) over a period of length $\tau$ for individuals with initial state $x_{0}=x$ is ${ }^{18}$

$$
\operatorname{MPX}_{\tau}(x)=\frac{\partial}{\partial b} \mathbb{E}\left[\int_{0}^{\tau} n\left(x_{t}\right) d t+\int_{0}^{\tau} d \psi\left(x_{t}\right) \mid x_{0}=x\right]
$$

\footnotetext{
${ }^{17}$ In the notional-consumption model of Section 3.1, the state variables are liquid wealth $b$ and income $y$. However, this is WLOG (e.g., the model can be extended to allow for illiquid assets).

${ }^{18}$ Our notation $\int_{0}^{\tau} d \psi\left(x_{t}\right)$ represents cumulative durables spending over $\tau$ years as the household's state evolves from $x_{0}$ to $x_{\tau}$. More precisely, normalizing the household's initial cumulative durables spending to $\psi_{0}=\psi\left(x_{0}\right)=0$, the notation means $\int_{0}^{\tau} d \psi_{t}=\psi_{\tau}=\psi\left(x_{\tau}\right)$ for a household with initial state $x_{0}$.
} 
i.e., the expected change in cumulative expenditure given a change in liquid wealth.

The extension with durables presented in Section 3.2 leads to a simple formula for converting notional consumption to expenditures and hence MPCs into MPXs:

Proposition 2 (The Marginal Propensity for Expenditure) The nondurable, durable, and total expenditure over a period $\tau$ defined in equation $(13)$ satisfy $X_{\tau}^{n}=(1-s) C_{\tau}$, $X_{\tau}^{D}=\frac{\delta s}{r+\delta} C_{\tau}+D_{\tau}-D_{0}$, and $X_{\tau}=\left(1-s+\frac{\delta s}{r+\delta}\right) C_{\tau}+D_{\tau}-D_{0}$, with $D_{\tau}=\frac{s}{r+\delta} c_{\tau}$. $C_{\tau}$ is the cumulative notional consumption flow defined in equation (2), and $c_{\tau}$ is consumption at time $\tau$.

Hence the Marginal Propensity for Expenditure (MPX) over a period $\tau$ is given by:

$$
M P X_{\tau}(x)=\left(1-s+\frac{\delta s}{r+\delta}\right) M P C_{\tau}(x)+\frac{s}{r+\delta} \times \frac{\partial}{\partial b} \mathbb{E}\left[c\left(x_{\tau}\right) \mid x_{0}=x\right]
$$

The MPX in equation (18) has three components: (i) nondurable spending of $(1-s) M P C_{\tau}(x)$, (ii) spending to replace depreciated durables of $\left(\frac{\delta s}{r+\delta}\right) M P C_{\tau}(x)$, and (iii) spending to increase the durable stock at time $\tau$ of $\frac{s}{r+\delta} \times \frac{\partial}{\partial b} \mathbb{E}\left[c\left(x_{\tau}\right) \mid x_{0}=x\right]$. These components follow from the nondurable and durable expenditures given in equations (14) and (15), respectively.

Additionally, the MPX in equation (18) can be broken down into a nondurable MPX and a durable MPX:

$$
\begin{aligned}
M P X_{\tau}^{n}(x) & =(1-s) M P C_{\tau}(x), \\
M P X_{\tau}^{D}(x) & =\left(\frac{\delta s}{r+\delta}\right) M P C_{\tau}(x)+\frac{s}{r+\delta} \times \frac{\partial}{\partial b} \mathbb{E}\left[c\left(x_{\tau}\right) \mid x_{0}=x\right],
\end{aligned}
$$

so that $M P X_{\tau}(x)=M P X_{\tau}^{n}(x)+M P X_{\tau}^{D}(x)$.

Proof. See Appendix A.2.

Proposition 2 provides a simple and tractable formula for converting MPCs into MPXs. ${ }^{19}$ Only two additional ingredients are needed: the change in expected notional consumption

\footnotetext{
${ }^{19}$ We could have also defined cumulative durable expenditure in equation (13) to include the interest payments that are sacrificed by holding durables, i.e., $X_{\tau}^{D}=\int_{0}^{\tau} d \psi_{t}+\int_{0}^{\tau} r D_{t} d t$. In this case, the MPX simplifies even further:

$$
M P X_{\tau}(x)=M P C_{\tau}(x)+\frac{s}{r+\delta} \times \frac{\partial}{\partial b} \mathbb{E}\left[c\left(x_{\tau}\right) \mid x_{0}=x\right]
$$

Since $r$ is typically small, this alternative definition of the MPX will be quantitively similar to equation (18).
} 
at time $\tau$, and the new parameters $s$ and $\delta$. The former can be calculated numerically from the solution of the notional-consumption model alone by using the Feynman-Kac formula. The latter can be calibrated. Here, we use BEA data to calibrate durable share $s=0.125$ and depreciation rate $\delta=0.22$ (see Appendix C).

Since $\left(1-s+\frac{\delta s}{r+\delta}\right) \approx 1$ when $r \approx 0$, comparing the MPC in equation (16) to the MPX in equation (18) shows that the MPX will typically be greater than the MPC. This property is intuitive, since durable expenditure is front-loaded relative to durable consumption. This timing difference between MPCs and MPXs is detailed in Section 4.2 below.

We emphasize that the MPX may take values far larger than one. In our extended model, the ability for consumers to borrow against durables allows for them to turn liquidity injections into larger durable purchases. Empirically, we also see evidence of expenditures exceeding liquidity injections. For example, Parker et al. (2013) document a large response of automobile purchases to the 2008 fiscal stimulus, Aaronson et al. (2012) find that debtfinanced durable spending increases sharply following minimum wage hikes, and Fagereng et al. (2019a) estimate MPXs above 1 for small lottery winnings.

This section defines the MPC and the MPX out of an infinitesimal increase in liquid wealth. However, tax rebates and fiscal stimulus payments increase liquid wealth discretely. The definition of the MPC and the MPX are easily extended to discrete liquidity injections. See Appendix D for details.

Finally, equations (19) and (20) show how to map the notional MPC into separate nondurable and durable MPXs. This can be useful because empirical studies often report decomposed MPX estimates. Section 4.4 discusses some examples.

\subsection{Comparing the Timing of MPCs and MPXs}

MPXs are typically more front-loaded than MPCs because a one-time expenditure on durables provides long-lasting consumption flows. To highlight how the MPC and the MPX dynamically relate to one another, we assume that $r \approx 0$ and that $\frac{\partial}{\partial b} \mathbb{E}\left[c\left(x_{\tau}\right) \mid x_{0}=x\right]$ is roughly 
constant in $\tau$ in order to derive the following approximation: ${ }^{20}$

$$
M P X_{\tau}(x) \approx\left(1+\frac{s}{\delta} \times \frac{1}{\tau}\right) M P C_{\tau}(x)
$$

In this approximation, the term $1 \times M P C_{\tau}(x)$ captures both nondurable spending and spending to replace depreciated durables, while $\frac{s}{\delta} \times \frac{M P C_{\tau}(x)}{\tau}$ captures spending to increase the durable stock over period $\tau$ (i.e., $D_{\tau}-D_{0}$ ). Over short horizons the $\frac{1}{\tau}$ will dominate and therefore MPX $\gg$ MPC, meaning that over short horizons the MPX is driven mainly by initial spending on durables. This is intuitive: durable expenditure is lumpy and happens right after a liquidity injection, whereas consumption flows take time to cumulate. Over longer horizons, as $\tau$ increases and consumption flows are steadily cumulated from the initial durable expenditure, the MPC converges to the MPX.

\subsection{Discrete-Time Specification}

Our MPX result in equation (18) is derived in a continuous-time model. Since many consumption-saving models are written in discrete time, Proposition 7 in Appendix B provides a discrete-time version of our MPX result. Though the discrete-time version is less tractable, the discrete-time MPX takes on a particularly simple form when studied over the first period after a shock, which we present below.

Assume that we have a discrete-time notional-consumption model with a given period length, say one quarter or one year. Denote by $r$ and $\delta$ the interest rate and durable depreciation rate over that discrete time period. This is a slight abuse of notation because these discrete-time rates differ slightly from the instantaneous continuous-time rates in the preceding sections. Similarly denote by $M P C_{\tau}(x)$ and $M P X_{\tau}(x)$ the notional MPC and MPX over $\tau$ discrete time periods (again these differ slightly from their continuous-time counterparts). With this notation we have:

Proposition 3 (The One-Period Marginal Propensity for Expenditure) The discretetime MPX over one period is simply:

$$
M P X_{1}(x)=\left(1-s+\frac{s}{r+\delta}\right) M P C_{1}(x) .
$$

\footnotetext{
${ }^{20}$ We thank Greg Kaplan for this helpful suggestion.
} 
Analogously to Proposition 2, the one-period MPX in equation (21) can be broken down into one-period nondurable and durable MPXs:

$$
\begin{aligned}
M P X_{1}^{n}(x) & =(1-s) M P C_{1}(x), \\
M P X_{1}^{D}(x) & =\left(\frac{s}{r+\delta}\right) M P C_{1}(x),
\end{aligned}
$$

so that $M P X_{1}(x)=M P X_{1}^{n}(x)+M P X_{1}^{D}(x)$.

Proof. See Appendix B.

Equation (21) provides a powerful method for converting one-period MPCs into MPXs: take the MPC and multiply by $\left(1-s+\frac{s}{r+\delta}\right)$ to recover the MPX. This conversion from MPCs to MPXs involves no additional modeling, because the durable share $s$ and the depreciation rate $\delta$ are empirical objects that can be calibrated, for example, by using BEA data (see Appendix C). ${ }^{21}$

We highlight the power of this simple formula for the standard case of discrete-time models written at a quarterly frequency. In Appendix $\mathrm{C}$ we calibrate durable share $s=0.125$ and quarterly durable depreciation rate $\delta=0.054$. For small quarterly interest rates $r \approx 0$, this means $\left(1-s+\frac{s}{r+\delta}\right) \approx 3$. Thus, equation $(21)$ provides a very simple rule-of-thumb for converting quarterly MPCs into quarterly MPXs:

Remark 4 (The "MPC Times 3" Rule-of-Thumb) The one-quarter MPX is roughly three times the one-quarter $M P C$.

\subsection{Taking the MPX Mapping to the Data}

Our rule-of-thumb formula in Remark 4 is derived using only our extended model with durables and our calibration of the durable consumption share and depreciation rate. Hence, a good validation exercise is to study the extent to which our MPX mapping holds in the data.

\footnotetext{
${ }^{21}$ The one-period discrete-time MPX in equation (21) is comparable to the continuous-time MPX in equation (18), with the main difference being that the discrete-time MPX is "missing" the durable depreciation component in equation (18) of $\frac{\delta s}{r+\delta} M P C_{\tau}(x)$. This term reappears in discrete-time MPXs over longer horizons (see Proposition 7 in Appendix B), but it doesn't affect the one-period MPX since durable depreciation doesn't occur until the period after durables are purchased.
} 
Using equations (21) and (22) from our one-period MPX, we find that the total MPX is $\left(1+\frac{s}{(r+\delta)(1-s)}\right)$ times the nondurable MPX, or 3.6 in our calibration. This mapping performs well empirically. As reviewed in Section 2, Parker et al. (2013) estimate quarterly nondurable MPXs of 12-30\% and quarterly total MPXs ranging from 50-90\%, while Kueng (2018) finds a quarterly nondurable MPX of $25 \%$ and a quarterly total MPX of $73 \%$. In both cases, the quarterly total MPX is roughly three to four times the quarterly nondurable MPX.

\section{Discussion of MPX Shortcomings and Partial Fixes}

\subsection{Discussion of MPX Shortcomings}

Though our model with durables is highly tractable, it is also stylized. Our simple MPX formula fails to provide an accurate description of reality in two important scenarios: interest rate shocks and negative liquidity injections. We therefore recommend that our MPX formula be used to study the expenditure response to positive liquidity injections, holding interest rates constant. However, our MPX formula can be generalized so that it performs more accurately in the case of negative liquidity injections, which we discuss below in Section 5.2.

On interest rate shocks, Assumption 3 assumes that durables generate consumption flow $f=r+\delta$. This means that the durable stock needed to attain a given consumption flow varies with $r$. This assumption is reverse-engineered to maintain an isomorphism with the notional-consumption model (see footnote 16), and is not intended to capture reality. Auclert (2019) and McKay and Wieland (2019) provide richer models detailing the channels through which durable spending is affected by interest rate changes.

On negative liquidity injections, Berger and Vavra (2015) find that the durable response to liquidity injections is asymmetric. Households buy durables in response to positive liquidity injections, but wait for durables to depreciate in response to negative liquidity injections. In our MPX formula (equation (18)), the expenditure response to positive and negative liquidity injections is symmetric. However, we show in Section 5.2 that our MPX formula can be generalized so that it performs more accurately in these scenarios. 


\subsection{Accounting for Adjustment Frictions in Reduced Form}

The purchase and sale of durable goods is subject to various adjustment frictions (e.g., Berger and Vavra, 2015), which we have heretofore omitted. As discussed in Section 5.1, we view such frictions to be less important in the case of positive liquidity injections. Nonetheless, our MPX technology can be modified to account for adjustment frictions in reduced form.

The key idea is that such adjustment frictions can be represented as time variation in the durable share $s$. For example, Berger and Vavra (2015) argue that after a negative liquidity injection, adjustment frictions will result in households letting durables depreciate rather than immediately being sold. This results in a durable share that rises on impact and then slowly reverts back to its normal level as durables depreciate. We capture such behavior (in reduced form) by letting the preference parameter $s$ in the CES aggregator (8) vary over time. Though our modeling device provides no guidance on how durable share $s$ should vary over time, this added flexibility allows the researcher to feed in alternate time-paths for the durable share.

Generalizing the MPX formula to allow for a time-varying durable share, we now have:

Corollary 5 (The MPX with a Time-Varying Durable Share) Let $s_{t}$ denote the time$t$ durable share. The Marginal Propensity for Expenditure over $\tau$ years is given by:

$M P X_{\tau}(x)=\frac{\partial}{\partial b} \mathbb{E}\left[\int_{0}^{\tau}\left(1-s_{t}+\frac{\delta s_{t}}{r+\delta}\right) c\left(x_{t}\right) d t \mid x_{0}=x\right]+\frac{1}{r+\delta} \times \frac{\partial}{\partial b} \mathbb{E}\left[s_{\tau} c\left(x_{\tau}\right) \mid x_{0}=x\right]$.

When $r \approx 0$ the MPX in equation (24) is simply:

$$
M P X_{\tau}(x) \approx M P C_{\tau}(x)+\frac{1}{\delta} \times \frac{\partial}{\partial b} \mathbb{E}\left[s_{\tau} c\left(x_{\tau}\right) \mid x_{0}=x\right],
$$

and this approximation is exact when $r=0$.

Proof. See Appendix A.3.

The MPX with a time-varying durable share in equation (24) allows for an analysis of how household expenditures change due to durable adjustment frictions. ${ }^{22}$ First, consider

\footnotetext{
${ }^{22}$ Though the generalized MPX in equation (24) takes on a more complicated form than the baseline MPX in equation (18), the same numerical methods can be used to calculate either equation in a notionalconsumption model.
} 
a negative liquidity injection, which households respond to by letting durables depreciate (Berger and Vavra, 2015). In this case, durable share $s_{t}$ temporarily rises following the negative liquidity shock, which reduces the extent to which expenditure drops in the shortrun. Second, households may be slow to increase durable purchases following a positive liquidity injection, due possibly to adjustment costs (e.g., Bernanke, 1985; Caballero, 1993) or procrastination (e.g., Laibson et al., 2021). ${ }^{23}$ In this case, durable share $s_{t}$ temporarily falls before slowly returning to its typical level, causing the MPX to increase less quickly at first. Third, adjustment frictions may cause durable share $s_{t}$ to depend on the size of a liquidity injection (see e.g. Parker et al. (2013), Green et al. (2020), and Fuster et al. (2021) for discussions related to such composition effects).

\section{Conclusion}

Policy and empirical analyses of consumer spending often focus on the response of consumer expenditures to liquidity injections. But economists' benchmark model studies notional consumption. To bridge the gap, this paper develops a simple, parsimonious, and portable modeling device that converts MPCs into MPXs. Our formula is particularly simple in quarterly models. When our framework is calibrated, the MPX is approximately three times the notional MPC. Our modeling device is easy to use and matches the available empirical evidence.

\footnotetext{
${ }^{23}$ Procrastination may also change the composition of purchased durables, since we conjecture that households will be more likely to procrastinate on purchasing durables that do not bring excitement, such as replacing an aging hot water storage tank, than on durables that are exciting to purchase, such as a new sports car.
} 


\section{References}

Aaronson, Daniel, Sumit Agarwal, and Eric French, "The Spending and Debt Response to Minimum Wage Hikes," American Economic Review, 2012, 102 (7), 3111-39.

Abel, Andrew B., "Consumption and Investment," Handbook of Monetary Economics, 1990, 2, 725-778.

Achdou, Yves, Jiequn Han, Jean-Michel Lasry, Pierre-Louis Lions, and Benjamin Moll, "Income and Wealth Distribution in Macroeconomics: A Continuous-Time Approach," The Review of Economic Studies, 2021.

Aguiar, Mark and Erik Hurst, "Consumption Versus Expenditure," Journal of Political Economy, 2005, 113 (5), 919-948.

Auclert, Adrien, "Monetary Policy and the Redistribution Channel," American Economic Review, 2019, 109 (6), 2333-67.

_, Matthew Rognlie, and Ludwig Straub, "The Intertemporal Keynesian Cross," NBER w25020, 2018.

Beraja, Martin and Christian K. Wolf, "Demand Composition and the Strength of Recoveries," NBER w29304, 2021.

Berger, David and Joseph Vavra, "Consumption dynamics during recessions," Econometrica, 2015, 83 (1), 101-154.

Bernanke, Ben, "Adjustment Costs, Durables, and Aggregate Consumption," Journal of Monetary Economics, 1985, 15 (1), 41-68.

Bureau of Economic Analysis, NIPA Handbook: Concepts and Methods of the U.S. National Income and Product Accounts, U.S. Department of Commerce, 2020.

Caballero, Ricardo J., "Durable Goods: An Explanation for Their Slow Adjustment," Journal of Political Economy, 1993, 101 (2), 351-384.

Crawley, Edmund and Andreas Kuchler, "Consumption Heterogeneity: Micro Drivers and Macro Implications," 2020. 
Fagereng, Andreas, Martin Blomhoff Holm, and Gisle James Natvik, "MPC Heterogeneity and Household Balance Sheets," SSRN 3399027, 2019.

_, , , Benjamin Moll, and Gisle Natvik, "Saving Behavior Across the Wealth Distribution: The Importance of Capital Gains," NBER w26588, 2019.

Fuster, Andreas, Greg Kaplan, and Basit Zafar, "What Would You Do with $\$ 500$ ? Spending Responses to Gains, Losses, News, and Loans," The Review of Economic Studies, 2021, 88 (4), 1760-1795.

Ganong, Peter and Pascal Noel, "Consumer Spending during Unemployment: Positive and Normative Implications," American Economic Review, 2019, 109 (7), 2383-2424.

_ , Fiona Greig, Max Liebeskind, Pascal Noel, Daniel Sullivan, and Joseph Vavra, "Spending and Job Search Impacts of Expanded Unemployment Benefits: Evidence from Administrative Micro Data," Mimeo, 2021.

Green, Daniel, Brian T. Melzer, Jonathan A. Parker, and Arcenis Rojas, "Accelerator or Brake? Cash for Clunkers, Household Liquidity, and Aggregate Demand," American Economic Journal: Economic Policy, 2020, 12 (4), 178-211.

Hale, Galina, Bart Hobijn, Fernanda Nechio, Doris Wilson et al., "How Much Do We Spend on Imports?," FRBSF Economic Letter, 2019, 1.

Hayashi, Fumio, "The Permanent Income Hypothesis and Consumption Durability: Analysis Based on Japanese Panel Data," The Quarterly Journal of Economics, 1985, 100 (4), 1083-1113.

Jappelli, Tullio and Luigi Pistaferri, "Fiscal Policy and MPC Heterogeneity," American Economic Journal: Macroeconomics, 2014, 6 (4), 107-36.

Kaplan, Greg and Giovanni L. Violante, "A Model of the Consumption Response to Fiscal Stimulus Payments," Econometrica, 2014, 82 (4), 1199-1239.

_ and _ , "The Marginal Propensity to Consume in Heterogeneous Agent Models," Mimeo, 2021. 
_, Benjamin Moll, and Giovanni L. Violante, "The Great Lockdown and the Big Stimulus: Tracing the Pandemic Possibility Frontier for the US," 2020.

Kueng, Lorenz, "Excess Sensitivity of High-Income Consumers," The Quarterly Journal of Economics, 2018, 133 (4), 1693-1751.

Laibson, David, Peter Maxted, and Benjamin Moll, "Present Bias Amplifies the Household Balance-Sheet Channels of Macroeconomic Policy," Mimeo, 2021.

Lusardi, Annamaria, "Permanent income, current income, and consumption: Evidence from two panel data sets," Journal of Business \& Economic Statistics, 1996, 14 (1), 81-90.

Maggio, Marco Di, Amir Kermani, and Christopher J. Palmer, "How Quantitative Easing Works: Evidence on the Refinancing Channel," The Review of Economic Studies, 2020, 87 (3), 1498-1528.

_ , _, and Kaveh Majlesi, "Stock Market Returns and Consumption," The Journal of Finance, 2020, 75 (6), 3175-3219.

_ , _, Benjamin J. Keys, Tomasz Piskorski, Rodney Ramcharan, Amit Seru, and Vincent Yao, "Interest Rate Pass-Through: Mortgage Rates, Household Consumption, and Voluntary Deleveraging," American Economic Review, 2017, 107 (11), 3550-88.

Mankiw, N. Gregory, "Hall's Consumption Hypothesis and Durable Goods," Journal of Monetary Economics, 1982, 10 (3), 417-425.

McKay, Alisdair and Johannes F. Wieland, "Lumpy Durable Consumption Demand and the Limited Ammunition of Monetary Policy," NBER w26175, 2019.

Padula, Mario, "Consumer Durables and the Marginal Propensity to Consume out of Permanent Income Shocks," Research in Economics, 2004, 58 (4), 319-341.

Parker, Jonathan A., Nicholas S. Souleles, David S. Johnson, and Robert McClelland, "Consumer Spending and the Economic Stimulus Payments of 2008," American Economic Review, 2013, 103 (6), 2530-53.

Yogo, Motohiro, "A Consumption-Based Explanation of Expected Stock Returns," The Journal of Finance, 2006, 61 (2), 539-580. 


\section{A Continuous-Time Proofs}

\section{A.1 Proof of Lemma 1}

The household's intratemporal problem is as follows: minimize expenditure $n+(r+\delta) D$

subject to attaining a level of $c$ given by equation (8). Equivalently, defining $d:=f D$, the household solves

$$
E(c)=\min _{n, d}\left\{n+\frac{r+\delta}{f} d \quad \text { s.t. } \quad\left(s^{\frac{1}{\eta}} d^{\frac{\eta-1}{\eta}}+(1-s)^{\frac{1}{\eta}} n^{\frac{\eta-1}{\eta}}\right)^{\frac{\eta}{\eta-1}} \geq c\right\}
$$

Defining $R:=(r+\delta) / f$ and using the standard CES results, the demand for $n$ and $d$ and the expenditure function $E(c)$ are given by

$$
\begin{aligned}
n & =\frac{1-s}{s R^{1-\eta}+1-s} P c \\
d & =\frac{s R^{-\eta}}{s R^{1-\eta}+1-s} P c \\
E(c) & =P c \\
P & =\left(s R^{1-\eta}+1-s\right)^{\frac{1}{1-\eta}}
\end{aligned}
$$

\section{A.2 Proof of Proposition 2: Calculating the Marginal Propensity for Expenditure (MPX)}

Following from equation (14) we have $X_{\tau}^{n}=(1-s) C_{\tau}$, as asserted in the Proposition. Following from equation (15) the total expenditure on both nondurables and durables defined in equation (13) is given by

$$
X_{\tau}=X_{\tau}^{n}+X_{\tau}^{D}=\int_{0}^{\tau} n_{t} d t+\int_{0}^{\tau} \delta D_{t} d t+D_{\tau}-D_{0} .
$$

Next, from (3) we have

$$
D_{\tau}=\frac{s}{r+\delta} c_{\tau}
$$

Intuitively, generating a notional consumption flow $c_{\tau}$ at time $\tau$ requires holding a durable stock $D_{\tau}$ defined by equation (26). The reason is that, by Lemma 1 , generating notional consumption flow $c_{\tau}$ requires generating durable consumption flow $f D_{\tau}=s c_{\tau}$. Since $f=r+\delta$ 
by Assumption 3, this requires holding a durable stock of $D_{\tau}=s c_{\tau} /(r+\delta)$. Using equations (26) and (2) in equation (15) yields the expressions for $X_{\tau}^{D}$ in the Proposition.

Next consider the MPX defined in equation (17). Using equations (13), (14), and (15) in the definition of the MPX in (17) we have

$$
\begin{aligned}
M P X_{\tau}(x) & =\frac{\partial}{\partial b} \mathbb{E}\left[(1-s) \int_{0}^{\tau} c\left(x_{t}\right) d t+\int_{0}^{\tau} \delta D\left(x_{t}\right) d t+D\left(x_{\tau}\right)-D_{0} \mid x_{0}=x\right] \\
& =\frac{\partial}{\partial b} \mathbb{E}\left[\left(1-s+\frac{\delta s}{r+\delta}\right) \int_{0}^{\tau} c\left(x_{t}\right) d t \mid x_{0}=x\right]+\frac{s}{r+\delta} \frac{\partial}{\partial b} \mathbb{E}\left[c\left(x_{\tau}\right) \mid x_{0}=x\right] \\
& =\left(1-s+\frac{\delta s}{r+\delta}\right) M P C_{\tau}(x)+\frac{s}{r+\delta} \frac{\partial}{\partial b} \mathbb{E}\left[c\left(x_{\tau}\right) \mid x_{0}=x\right]
\end{aligned}
$$

where the second equality uses equation (26). This is equation (18) in the Proposition.

\section{A.3 Proof of Corollary 5: The MPX with a Time-Varying Durable Share}

To capture time variation in the durable share, we now allow the preference parameter $s$ in the CES aggregator (8) to vary over time. We denote this time-varying durable share by $s_{t}$. With this time-varying durable share, equation (3) becomes

$$
c_{t}=n_{t}+(r+\delta) D_{t}, \quad \text { with } \quad n_{t}=\left(1-s_{t}\right) \times c_{t} \quad \text { and } \quad(r+\delta) D_{t}=s_{t} \times c_{t}
$$

The rest of the proof follows similar steps as the proof of Proposition 2 simply replacing $s$ by $s_{t}$. In particular, the MPX defined in equation (17) becomes:

$$
\begin{aligned}
M P X_{\tau}(x) & =\frac{\partial}{\partial b} \mathbb{E}\left[\int_{0}^{\tau}\left(1-s_{t}\right) c\left(x_{t}\right) d t+\int_{0}^{\tau} \delta D\left(x_{t}\right) d t+D\left(x_{\tau}\right)-D_{0} \mid x_{0}=x\right] \\
& =\frac{\partial}{\partial b} \mathbb{E}\left[\int_{0}^{\tau}\left(1-s_{t}+\frac{\delta s_{t}}{r+\delta}\right) c\left(x_{t}\right) d t \mid x_{0}=x\right]+\frac{1}{r+\delta} \frac{\partial}{\partial b} \mathbb{E}\left[s_{\tau} c\left(x_{\tau}\right) \mid x_{0}=x\right]
\end{aligned}
$$

where the second equality uses equation $\left(3^{\prime}\right)$ that $D_{t}=\frac{s t}{r+\delta} c_{t}$. This is equation (24) in the Corollary. 


\section{B Discrete-Time Mapping from MPCs to MPXs}

This Appendix presents a mapping from MPCs to MPXs that applies to discrete-time models of notional consumption. In particular it provides the derivations for Section 4.3 in the main text and proves Proposition 3. Our discrete-time construction is similar to the continuoustime construction presented in Section 3, and we leave many details to that section.

\section{B.1 Benchmark: Single Notional Consumption Good}

In discrete time, we again begin by presenting a standard consumption-saving model with a single notional consumption good, which we refer to as the Benchmark.

The Liquid Wealth Budget Constraint. The dynamic budget constraint for liquid wealth $b_{t}$ is:

$$
b_{t}=(1+r) b_{t-1}+y_{t}-c_{t}
$$

subject to the borrowing constraint $b_{t} \geq \underline{b}$.

The state variables of the notional-consumption model are $x_{t}=\left(b_{t-1}, y_{t}\right)$. We denote by

$$
C_{\tau}=\sum_{t=0}^{\tau-1} c_{t}
$$

the cumulative notional consumption flow over $\tau$ periods.

\section{B.2 Extension: An Isomorphic Model with Durables}

We now introduce an extended model featuring the purchase of durable goods that is isomorphic to the notional-consumption model in Section B.1. See Abel (1990) and Auclert et al. (2018) for related comparisons of discrete-time notional-consumption models to models with both nondurables and durables.

Setup with Durables. Let $n_{t}$ denote nondurable consumption, and let $D_{t}$ denote the household's stock of durables. Durable stock $D_{t}$ provides durable consumption as a flow, 
and depreciates at rate $\delta$ satisfying $r+\delta>0$. The household continues to save in liquid bank holdings, which we denote by $\ell_{t}$. In our discrete-time model we continue to maintain Assumption 1 that the durables market is perfectly liquid. We let $\varphi_{t}$ denote the household's purchases/sales of durables in period $t$.

Model Timing. We adopt one slightly nonstandard timing convention to allow for closer comparability with the continuous-time specification presented in the main text. Specifically, we assume that durable purchases are made before interest is incurred. Given this timing convention, the household's budget constraint can be written as

$$
\begin{aligned}
\ell_{t} & =(1+r)\left(\ell_{t-1}-\varphi_{t}\right)+y_{t}-n_{t}, \\
D_{t} & =(1-\delta) D_{t-1}+\varphi_{t}
\end{aligned}
$$

where our timing convention implies that the household's returns are earned on liquid wealth net of durable purchases, $(1+r)\left(\ell_{t-1}-\varphi_{t}\right)$. The notation in equations (29) and (30) remains similar to equations (4) and (5) except that we now use variable $\varphi_{t}$ to denote the household's spending on durables in period $t$. Given our timing convention, the household's total wealth at the end of period $t$ is given by $b_{t}=\ell_{t}+(1-\delta) D_{t}$.

Our timing convention is not necessary, but the benefit is that it shifts the cost of durable consumption forward in time and simplifies the user cost of durables. Specifically, the user cost of durables here will be $r+\delta$, just like in our continuous-time setup. Without our perturbed timing convention, the user cost would instead have been $\frac{r+\delta}{1+r} \cdot{ }^{24}$

Because Assumption 1 imposes that the household can borrow against (the non-depreciated part of) durables, the borrowing constraint now applies to the household's total liquid wealth holdings $b_{t}=\ell_{t}+(1-\delta) D_{t}$ :

$$
\ell_{t}+(1-\delta) D_{t} \geq \underline{b}
$$

Given Assumption 1 we can work with only one state variable for household wealth, namely total liquid wealth $b_{t}=\ell_{t}+(1-\delta) D_{t}$. To this end, use (29) and (30) to sum $\ell_{t}+(1-\delta) D_{t}$,

\footnotetext{
${ }^{24}$ Without our timing convention, durables purchased in period $t$ affect the household's wealth in period $t+1$, and hence the present-value user cost is $\frac{r+\delta}{1+r}$ (where the term $\frac{1}{1+r}$ reflects discounting from period $t+1$ to period $t$ ). Our alternate timing setup effectively moves durable purchases forward in time.
} 
which gives

$$
\begin{aligned}
b_{t} & =(1+r)\left(\ell_{t-1}-\varphi_{t}\right)+y_{t}-n_{t}+(1-\delta) D_{t} \\
& =(1+r)\left(\left(b_{t-1}-(1-\delta) D_{t-1}\right)-\varphi_{t}\right)+y_{t}-n_{t}+(1-\delta) D_{t} \\
& =(1+r)\left(b_{t-1}-D_{t}\right)+y_{t}-n_{t}+(1-\delta) D_{t} \\
& =(1+r) b_{t-1}+y_{t}-n_{t}-(r+\delta) D_{t} .
\end{aligned}
$$

A key implication of Assumption 1 is therefore that a relevant measure of the household's expenditure on durables is the user cost $(r+\delta) D_{t}$.

As in the continuous-time model we continue to maintain Assumptions 2 and 3 here. Similar to key equation (3), these assumptions lead to the household choosing

$$
n_{t}=(1-s) \times c_{t}, \quad(r+\delta) D_{t}=s \times c_{t}, \quad \text { and } \quad n_{t}+(r+\delta) D_{t}=c_{t} .
$$

Isomorphism to Notional-Consumption Model. We are now ready to prove the isomorphism between the extension with durables and our benchmark notional-consumption model.

Proposition 6 Under Assumptions 1 to 3, the extension with durables is isomorphic to the notional-consumption model. In particular, total liquid wealth $b_{t}=\ell_{t}+(1-\delta) D_{t}$ evolves as

$$
b_{t}=(1+r) b_{t-1}+y_{t}-c_{t}
$$

subject to the borrowing constraint $b_{t} \geq \underline{b}$. This is identical to the law of motion and borrowing constraint for $b_{t}$ in equation (27).

Proof. Assumption 1 implies that equation (32) holds. Assumptions 2 and 3 imply that equation (33) holds. Substituting (33) into (32) yields equation (34).

Note that the extended model has exactly the same state variables $x_{t}=\left(b_{t-1}, y_{t}\right)$ as the notional-consumption model.

Cumulative Expenditure Flows. Analogous to the cumulative notional consumption flow in equation (28), we here define $X_{\tau}$ to be the cumulative expenditure over a period $\tau$, 
which is the sum of cumulative expenditure on nondurables $X_{\tau}^{n}$ and durables $X_{\tau}^{D}$ :

$$
X_{\tau}=X_{\tau}^{n}+X_{\tau}^{D}, \quad \text { where } \quad X_{\tau}^{n}=\sum_{t=0}^{\tau-1} n_{t} \quad \text { and } \quad X_{\tau}^{D}=\sum_{t=0}^{\tau-1} \varphi_{t}
$$

The cumulative expenditure flow $X_{\tau}$ will form the basis for defining the MPX below.

\section{B.3 Results: The MPC and the MPX}

We now present our discrete-time construction for calculating MPXs from models featuring only a single notional consumption good.

First consider the discrete-time MPC in the notional-consumption model of Section B.1. The MPC is closely related to the cumulative notional consumption flow in equation (28). More precisely, the notional marginal propensity to consume (MPC) over $\tau$ periods for individuals with initial state $x_{0}=x$ is then

$$
M P C_{\tau}(x)=\frac{\partial}{\partial b} \mathbb{E}\left[\sum_{t=0}^{\tau-1} c\left(x_{t}\right) \mid x_{0}=x\right]
$$

Next consider the discrete-time MPX in the extended model of Section B.2. The MPX is closely related to the cumulative expenditure flow defined in equation (35). The marginal propensity for expenditure (MPX) over $\tau$ periods for individuals with initial state $x_{0}=x$ is

$$
M P X_{\tau}(x)=\frac{\partial}{\partial b} \mathbb{E}\left[\sum_{t=0}^{\tau-1} n\left(x_{t}\right)+\sum_{t=0}^{\tau-1} \varphi\left(x_{t}\right) \mid x_{0}=x\right]
$$

In discrete time, we now have the following formula for the MPXs that are implied by a notional-consumption model:

Proposition 7 (The Discrete-Time Marginal Propensity for Expenditure) The discretetime Marginal Propensity for Expenditure (MPX) over $\tau$ periods is given by:

$$
M P X_{\tau}(x)=(1-s) M P C_{\tau}(x)+\frac{\delta s}{r+\delta} M P C_{\tau-1}(x)+\frac{s}{r+\delta} \times \frac{\partial}{\partial b} \mathbb{E}\left[c\left(x_{\tau-1}\right) \mid x_{0}=x\right]
$$

Similar to equation (18), the discrete-time MPX in equation (38) has three components: (i) nondurable spending (first term), (ii) spending to replace depreciated durables (second term), 
and (iii) spending to increase the durable stock in period $\tau-1$ (third term).

When $\tau=1$, the equation simplifies to $M P X_{1}(x)=\left(1-s+\frac{s}{r+\delta}\right) M P C_{1}(x)$, exactly as in equation (21). Additionally, the MPX in equation (38) can be broken down into a nondurable MPX and a durable MPX:

$$
\begin{aligned}
M P X_{\tau}^{n}(x) & =(1-s) M P C_{\tau}(x), \\
M P X_{\tau}^{D}(x) & =\frac{\delta s}{r+\delta} M P C_{\tau-1}(x)+\frac{s}{r+\delta} \times \frac{\partial}{\partial b} \mathbb{E}\left[c\left(x_{\tau-1}\right) \mid x_{0}=x\right],
\end{aligned}
$$

so that $M P X_{\tau}(x)=M P X_{\tau}^{n}(x)+M P X_{\tau}^{D}(x)$.

Proof. See Appendix B.4.

\section{B.4 Proof of Proposition 7}

First consider nondurable expenditure $X_{\tau}^{n}$ defined in equation (35). From equation (33) we have

$$
X_{\tau}^{n}=(1-s) \sum_{t=0}^{\tau-1} c_{t}
$$

Next consider durable expenditure $X_{\tau}^{D}$ defined in equation (35). Using the property from budget constraint $(30)$ that $\varphi_{t}=D_{t}-(1-\delta) D_{t-1}$, we have

$$
\begin{aligned}
X_{\tau}^{D} & =\sum_{t=0}^{\tau-1} \varphi_{t} \\
& =D_{\tau-1}-(1-\delta) D_{-1}+\sum_{t=0}^{\tau-2} \delta D_{t}
\end{aligned}
$$

Therefore the total expenditure on both nondurables and durables defined in equation (35) is given by

$$
X_{\tau}=X_{\tau}^{n}+X_{\tau}^{D}=(1-s) \sum_{t=0}^{\tau-1} c_{t}+\sum_{t=0}^{\tau-2} \delta D_{t}+D_{\tau-1}-(1-\delta) D_{-1}
$$

Finally, from (33) we have

$$
D_{t}=\frac{s}{r+\delta} c_{t}
$$


Next consider the MPX defined in equation (37). Using equations (35) and (43) in the definition of the MPX in (37) we have

$$
\begin{aligned}
M P X_{\tau}(x) & =\frac{\partial}{\partial b} \mathbb{E}\left[(1-s) \sum_{t=0}^{\tau-1} c\left(x_{t}\right)+\sum_{t=0}^{\tau-2} \delta D\left(x_{t}\right)+D\left(x_{\tau-1}\right)-(1-\delta) D_{-1} \mid x_{0}=x\right] \\
& =\frac{\partial}{\partial b} \mathbb{E}\left[(1-s) \sum_{t=0}^{\tau-1} c\left(x_{t}\right)+\sum_{t=0}^{\tau-2} \delta D\left(x_{t}\right) \mid x_{0}=x\right]+\frac{\partial}{\partial b} \mathbb{E}\left[D\left(x_{\tau-1}\right) \mid x_{0}=x\right] \\
& =\frac{\partial}{\partial b} \mathbb{E}\left[(1-s) \sum_{t=0}^{\tau-1} c\left(x_{t}\right)+\frac{\delta s}{r+\delta} \sum_{t=0}^{\tau-2} c\left(x_{t}\right) \mid x_{0}=x\right]+\frac{\partial}{\partial b} \mathbb{E}\left[\frac{s}{r+\delta} c\left(x_{\tau-1}\right) \mid x_{0}=x\right] \\
& =(1-s) M P C_{\tau}(x)+\frac{\delta s}{r+\delta} M P C_{\tau-1}(x)+\frac{s}{r+\delta} \frac{\partial}{\partial b} \mathbb{E}\left[c\left(x_{\tau-1}\right) \mid x_{0}=x\right]
\end{aligned}
$$

where equation (44) is used to go from the second to the third line. This is equation (38) in the Proposition. In the case of $\tau=1$ (the one-period MPX), the second term drops out and the formula becomes simply $M P X_{1}(x)=\left(1-s+\frac{s}{r+\delta}\right) M P C_{1}(x)$.

\section{Calibration: Durable Share and Depreciation Rate}

We need to calibrate two parameters: durable depreciation rate $\delta$ and durable share $s$. For both parameters, we exclude housing and focus on consumer durables. This is because housing is unlikely to be adjusted over short (particularly quarterly) horizons following small liquidity injections. However, consumer durables still account for other inputs to housing quality that are more easily adjusted, such as home furnishings and durable household equipment. We also provide an alternate calibration below that includes housing, but emphasize that this alternate calibration with housing is more applicable to long-horizon MPXs.

Baseline Calibration. We calibrate the durable depreciation rate from the 2016 BEA Fixed Assets Accounts Tables. ${ }^{25}$ Table 1.1 reports a consumer durables stock of $\$ 5,162.5$ billion. Table 1.3 reports depreciation over the year of $\$ 1,025.5$ billion. This implies a discrete-time yearly depreciation rate of $\frac{1025.5}{5162.5}=0.199$ and a continuous-time depreciation rate of $\delta=-\log \left(1-\frac{1025.5}{5162.5}\right)=0.22$. This calibration means that durables have a half-life of 3.15 years. For Section 4.3 we also calibrate a quarterly (rather than yearly) depre-

\footnotetext{
${ }^{25}$ We use 2016 data because it is a "typical" year in the sense that it is not a recession/pandemic year, and we apply our MPX tool to the model of Laibson et al. (2021) who calibrate their model using 2016 data.
} 
ciation rate by mapping the yearly depreciation rate 0.199 into its quarterly counterpart $1-(1-0.199)^{1 / 4}=0.054$.

To calibrate durable share $s$, we use the 2016 NIPA data. The 2016 NIPA Report (Table 2.4.5) documents that total household consumption expenditures (in billions) are $\$ 12,693.3$. This is composed of durable goods of $\$ 1,345.2$, nondurable goods of $\$ 2,646.7$, and services of $\$ 8,701.4$. From services we subtract the rent of tenant-occupied housing and the imputed rent of owner-occupied housing $(\$ 1,964.8)$ in order to exclude marginal housing adjustments.

Assuming that households are in a static steady state, all durable expenditures are made to offset depreciation. ${ }^{26}$ Thus, $\delta D=1345.2$. Assuming $r=0$ for simplicity, the restriction that $f \equiv \delta$ implies that a household's total durable expenditures of $\delta D_{t}=f D_{t}=s c_{t}$. We also have $n_{t}=(1-s) c_{t}$. Letting both nondurable goods and services compose "nondurables", we have $n_{t}=2646.7+(8701.4-1964.8)=9383.3$. Total consumption is given by $c_{t}=\delta D+n_{t}=$ $1345.2+9383.3=10728.5$. Now, the durable share can be imputed from $\frac{\delta D}{c_{t}}$ :

$$
s=\frac{1345.2}{10728.5}=0.125
$$

Alternate Calibration with Housing. We also provide an alternate calibration that includes housing expenditures. Because housing is slow to adjust, this calibration is more applicable to long-horizon MPXs.

Again using the 2016 BEA Fixed Assets Accounts Tables to calibrate the depreciation rate, Table 1.1 reports a consumer durables stock of $\$ 5,162.5$ billion plus private residential assets of $\$ 20,211.9$ billion. Table 1.3 reports depreciation of $\$ 1,025.5$ billion on consumer durables plus $\$ 462.5$ billion on private residential assets. This implies a discretetime yearly depreciation rate of $\frac{1488}{25374.4}=0.059$ and a continuous-time depreciation rate of $\delta^{\text {incl-housing }}=-\log \left(1-\frac{1488}{25374.4}\right)=0.06 .{ }^{27}$ Finally, the corresponding quarterly (rather than yearly) depreciation rate is $1-(1-0.059)^{1 / 4}=0.015$.

Our calibration of the durable share that includes housing is again very similar to above. The one difference is that we now assign housing services ( $\$ 1,964.8$ billion) to durable consumption. ${ }^{28}$ Again using the assumption that all durable expenditures are made to offset de-

\footnotetext{
${ }^{26}$ This assumption allows us to convert durable expenditures into durable consumption. It is also not too far off: total durable spending is 1,345.2, while depreciation is 1,025.5.

${ }^{27}$ This calibration means that durables have a half-life of 11.5 years.

${ }^{28}$ This approach differs from the NIPA Report, which counts housing in services.
} 
preciation, total consumption is given by $c_{t}=\delta D+n_{t}=(1345.2+1964.8)+9383.3=12693.3$. Now, the durable share is $s^{\text {incl-housing }}=\frac{3310}{12693.3}=0.26$.

\section{MPCs and MPXs out of Discrete Liquidity Shocks}

Section 4 defines the MPC and the MPX over infinitesimal liquidity injections. Following Achdou et al. (2021), these definitions are easily extended to discrete liquidity injections.

We use $x+\chi$ as shorthand notation for point $x$ in the state space, plus a liquidity injection of size $\chi$. For a discrete liquidity injection of size $\chi$ the MPC is defined as:

$$
\operatorname{MPC}_{\tau}^{\chi}(x)=\frac{\mathbb{E}\left[\int_{0}^{\tau} c\left(x_{t}\right) d t \mid x_{0}=x+\chi\right]-\mathbb{E}\left[\int_{0}^{\tau} c\left(x_{t}\right) d t \mid x_{0}=x\right]}{\chi}
$$

The MPX out of a discrete liquidity injection is defined as:

$\operatorname{MPX}_{\tau}^{\chi}(x)=\frac{\mathbb{E}\left[\int_{0}^{\tau} n\left(x_{t}\right) d t+\int_{0}^{\tau} d \psi\left(x_{t}\right) \mid x_{0}=x+\chi\right]-\mathbb{E}\left[\int_{0}^{\tau} n\left(x_{t}\right) d t+\int_{0}^{\tau} d \psi\left(x_{t}\right) \mid x_{0}=x\right]}{\chi}$.

Following similar steps as the proof of Proposition 2, this MPX out of a discrete liquidity injection can be rewritten as:

$\operatorname{MPX}_{\tau}^{\chi}(x)=\left(1-s+\frac{\delta s}{r+\delta}\right) M P C_{\tau}^{\chi}(x)+\frac{s}{r+\delta}\left(\frac{\mathbb{E}\left[c\left(x_{\tau}\right) \mid x_{0}=x+\chi\right]-\mathbb{E}\left[c\left(x_{\tau}\right) \mid x_{0}=x\right]}{\chi}\right)$

which can again be calculated from a notional-consumption model given a calibration of parameters $s$ and $\delta$. Specifically, the MPC can be calculated numerically using the FeynmanKac formula (see Lemma 2 of Achdou et al. (2021) for details). Expected future consumption $\mathbb{E}\left[c\left(x_{\tau}\right) \mid x_{0}=x\right]$, which is used in the MPX calculation, can also be calculated numerically using the Feynman-Kac formula.

\section{E Application: Laibson, Maxted and Moll (2021)}

This appendix applies our MPX technology to the model of Laibson et al. (2021). This paper builds a heterogeneous-household model to understand how present-biased time preferences affect household budgeting decisions. The model features a liquid savings account and an 
illiquid home on the asset side of the balance sheet, and credit cards and mortgages on the liabilities side of the balance sheet. There is a single notional consumption good. The model is calibrated to match two empirical moments: the average quantity of credit card debt and the average mortgage loan-to-value ratio.

\begin{tabular}{ccc}
\hline & MPC & MPX \\
\hline$\frac{1}{4}$ Year & $13 \%$ & $32 \%$ \\
1 Year & $28 \%$ & $37 \%$ \\
2 Year & $41 \%$ & $46 \%$ \\
3 Year & $49 \%$ & $53 \%$ \\
\hline
\end{tabular}

Table 1: $\$ 1,000$ MPCs and MPXs

Notes: This table presents the average MPC and MPX out of a $\$ 1,000$ fiscal transfer in the Present-Bias Benchmark calibration of Laibson et al. (2021).

Table 1 reproduces the average MPC and MPX over various time horizons for the Laibson et al. (2021) model. There are two key takeaways from Table 1. First, MPXs are larger than MPCs. This is intuitive, as MPXs capture total expenditures rather than just notional consumption flows. Second, as highlighted in Section 4.2 there is a sizable difference between the timing of MPCs and MPXs, with MPXs being much more front-loaded than MPCs. Put differently, (notional) consumption lags expenditure. The one-quarter MPX is more than twice as large as the one-quarter MPC, but the cumulative three-year MPX is almost identical to the three-year MPC. This implies that households purchase a stock of durables at the time of the fiscal transfer, which subsequently provides flow-consumption to households going forward. 